\title{
Combination of chelating behaviour with molecular recognition as interaction for ligand exchange chromatography
}

\author{
Chuen Ying Liu, Ching Hung Chang, Sun Dsong Chyueh, Cho Chun Hu \\ Department of Chemistry, National Taiwan University, Taipei, Taiwan, ROC
}

Received: 30 November 1993/Revised: 22 February 1994

\begin{abstract}
A novel chelating resin was synthesized, composed of chemically bonded glycinocyclodextrin (S-CDG) to which silica gel was added as matrix and silanes with amino groups as spacer. It showed efficient complexation with transition metal cations. In this report the copper and zinc resin complexes were investigated for application as stationary phases for the separation of substituted phenol isomers. The results revealed that the copper resin complex has a high potential for this application.
\end{abstract}

\section{Introduction}

Ligand-exchange chromatography (LEC) is a well established method for separating complex-forming organic compounds. Much work has already been published on the separation of substituted phenols via LEC [1]. However, the separation of phenols on the basis of the combination of chelating behaviour and molecular recognition has so far not been dealt with. Since the glycine moiety has been used as mobile phase in ligand exchange mode for the resolution of underivatized amino acids [2-4], silica gel containing glycine as pendent group attached to the cyclodextrin (CD) cavity, i.e. glycinocyclodextrin resin, has been synthesized. Furthermore, the metal-resin complexes have also been investigated to evaluate their possible use as stationary phases for the LEC separation of phenolic compounds.

\section{Experimental}

Apparatus. The IR-spectra of the resin and its metal complexes in $\mathrm{KBr}$ were recorded by an infrared spectrophotometer (Perkin Elmer 983). A HPLC system (LDC/Milton Roy, USA) consisting of Constametric I and III pumps, Gradient Master (model 1601), a vari-

Correspondence to: Chuen Ying Liu able-wavelength detector (LDC, SpectroMonitor D), a Rheodyne injection valve (model 7125) and an integrator (Hitachi, D-2500) were used. A Radiometer $\mathrm{pH}-$ meter (Copenhagen, Denmark, PHM 61) was used to measure the $\mathrm{pH}$-values.

Chemicals. Most chemicals were of analytical reagent grade (E. Merck, Germany). 3-Aminopropyltriethoxysilane and phenolic compounds were supplied by Aldrich (Milwaukee, USA). Silica gel 60 G (E. Merck) was grinded to a particle size of 325-400 mesh.

Preparation of the sorbents. 3-Aminopropyltriethoxysilane $(5 \mathrm{~mL})$ was reacted with chloroform-washed silica gel $(4 \mathrm{~g})$ in toluene $(100 \mathrm{~mL})$ and with triethylamine $(0.5 \mathrm{~mL})$ as a catalyst at $75^{\circ} \mathrm{C}$ for $3 \mathrm{~h}$. The product(S) was washed sequentially with isopropanol, water and acetone. Tosyl chloride $(4 \mathrm{~g})$ in acetonitrile was dropwise added with vigorous shaking to an alkaline $\beta$-CD ( 4 g) solution $(0.15 \mathrm{~mol} / \mathrm{L}, 100 \mathrm{~mL})$. The mixture was reacted at room temperature for $1 \mathrm{~h}$ at $\mathrm{pH} 12$. The reaction was terminated by addition of hydrochloric acid $(1 \mathrm{~mol} / \mathrm{L})$. After filtration, the product was passed through the cationexchanger and the effluent was vacuum evaporated. The concentrated material was chiefly. $\beta$-CD tosylate. $6 \mathrm{~g}$ of it were added to product $\mathrm{S}(3 \mathrm{~g})$ in pyridine $(150 \mathrm{~mL})$. The mixture was reacted at $75^{\circ} \mathrm{C}$ for $40 \mathrm{~h}$. The resulting product was washed successively with pyridine, acetone and methanol and then dried overnight under vacuum at $50^{\circ} \mathrm{C}$. The product was S-CD. Glycylethyl ester hydrochloride salt $(6 \mathrm{~g})$ was added to a stirred solution of equal amounts of sodium hydroxide. The mixture was extracted with dichloromethane. S-CD (3 g) was added to the extract and reacted at $80^{\circ} \mathrm{C}$ for $72 \mathrm{~h}$. The product was washed with water and acetone and dried in air. The product was termed S-CD-G.

\section{Results and discussion}

Characterization of stationary phases. The tosylation step for the synthesis of the resin was followed according to Iwakura's method [5]. The binding sites of CD to the silanized silica gel might be the secondary hydroxyl 
Table 1. Capacity factors of selected substituted phenol isomers on S-CD-G-Zn column with varied compositions of the mobile phase ${ }^{a}$

\begin{tabular}{|c|c|c|c|c|c|}
\hline \multirow[t]{2}{*}{ Sample } & \multicolumn{5}{|c|}{ Capacity factors } \\
\hline & $35 / 65^{\mathrm{b}}$ & $45 / 55^{\mathrm{b}}$ & $50 / 50^{\mathrm{b}}$ & $30 / 70^{c}$ & $30 / 10 / 60$ \\
\hline Phenol & 0.86 & 0.14 & 0.06 & 0.43 & 0.66 \\
\hline 2-Chlorophenol & 1.55 & 0.14 & 0.06 & 0.95 & 0.93 \\
\hline 2,4-Dichlorophenol & 4.45 & 0.96 & 0.49 & 2.98 & 3.48 \\
\hline 2-Nitrophenol & 6.25 & 2.34 & 1.65 & 2.98 & 3.48 \\
\hline 4-Nitrophenol & 12.90 & 4.42 & 2.92 & 5.46 & 6.42 \\
\hline
\end{tabular}

${ }^{a}$ Flow rate: $0.5 \mathrm{~mL} \mathrm{~min}^{-1}$

b Ratio of $\mathrm{CH}_{3} \mathrm{OH}$ to $\mathrm{H}_{2} \mathrm{O}$

- Ratio of $\mathrm{CH}_{3} \mathrm{CN}$ to $\mathrm{H}_{2} \mathrm{O}$

d Ratio of $\mathrm{CH}_{3} \mathrm{OH}$ to $\mathrm{CH}_{3} \mathrm{CN}$ to $\mathrm{H}_{2} \mathrm{O}$

Table 2. Capacity factors of selected substituted phenol isomers on the $\mathrm{S}-\mathrm{CD}-\mathrm{G}-\mathrm{Cu}$ column with varied compositions of the mobile phase ${ }^{\mathrm{a}}$

\begin{tabular}{llllll}
\hline \multirow{2}{*}{ Sample } & \multicolumn{5}{l}{ Capacity factors } \\
\cline { 2 - 6 } & $40 / 60^{\mathrm{b}}$ & $50 / 50^{\mathrm{b}}$ & $63 / 35^{\mathrm{b}}$ & $30 / 70^{\mathrm{c}}$ & $30 / 10 / 60^{\mathrm{d}}$ \\
\hline Phenol & 0.58 & 0.43 & 0.35 & 0.71 & 0.35 \\
2-Chlorophenol & 1.23 & 0.72 & 0.35 & 1.13 & 0.68 \\
2,4-Dichlorophenol & 2.78 & 1.86 & 0.88 & 2.71 & 1.97 \\
2-Nitrophenol & 4.65 & 3.14 & 2.27 & 3.64 & 3.34 \\
4-Nitrophenol & 9.25 & 6.92 & 4.29 & 7.43 & 6.92 \\
\hline
\end{tabular}

${ }^{a}$ Flow rate: $0.5 \mathrm{~mL} \mathrm{~min}^{-1}$

${ }^{b}$ Ratio of $\mathrm{CH}_{3} \mathrm{OH}$ to $\mathrm{H}_{2} \mathrm{O}$

- Ratio of $\mathrm{CH}_{3} \mathrm{CN}$ to $\mathrm{H}_{2} \mathrm{O}$

${ }^{d}$ Ratio of $\mathrm{CH}_{3} \mathrm{OH}$ to $\mathrm{CH}_{3} \mathrm{CN}$ to $\mathrm{H}_{2} \mathrm{O}$

groups and glycine might be attached to the $C D$ via the primary hydroxyl groups. The product in acid solution develops a darkish green colour when reacted with chromium trioxide. This result gives evidence to the bonding of CD in silica gel. After each step of synthesis, elemental analysis of the product was carried out in order to assess the extent of the bonding reaction. The functionality of glycine to the final product was $0.4 \mathrm{mmol} \mathrm{g}^{-1}$. The adsorption capacities of the resin for $\mathrm{Co}(\mathrm{II}), \mathrm{Cu}(\mathrm{II}), \mathrm{Ni}(\mathrm{II})$ and $\mathrm{Zn}(\mathrm{II})$ in $\mathrm{pH} 5.2$ acetate buffer were $0.15,0.24,0.21$ and $0.29 \mathrm{mmol} \mathrm{g}^{-1}$, respectively.

Specific evidence of the covalently bonded CD group to silica gel is provided by the infrared absorption bands of the $\mathrm{C}-\mathrm{H}$ stretching, $2900 \mathrm{~cm}^{-1}$, and to the glycine group by the absorption bands of $\mathrm{C}=0,1750 \mathrm{~cm}^{-1}$. In the metal-resin complexes, vibrational evidence for the coordination of the glycine groups concerning $v(\mathrm{C}-\mathrm{O})$ and $v(\mathrm{~N}-\mathrm{H})$ is obvious. Furthermore, coordination causes these lines to move to smaller wave numbers and a new absorption line appears $\left(1550 \mathrm{~cm}^{-1}\right)$ in addition to that at $619 \mathrm{~cm}^{-1}$ for the copper-resin complex and $1440 \mathrm{~cm}^{-1}$ for the cobalt-resin complex.

The pKa-value of the resin and the stability constants of the metal-resin complexes were determined as described in the previous paper [6]. The pKa-value of the resin ligand is 11.2. The result is rational [7], as there is an electron-withdrawing group, $-\mathrm{C}=0$, besides the protonated amine. The values of the stability constants of

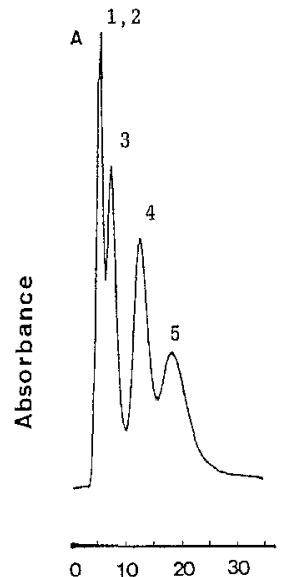

B

$c$

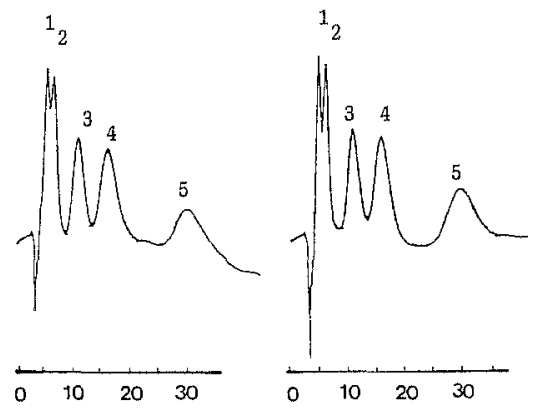

Retention Time/min

Fig. 1A-C. Separation of phenolic compounds. Stationary phase $(10 \times 4.6 \mathrm{~mm}$ i.d. $)$ : A: S-CD-G-Zn; B and C: S-CD-G-Cu. Mobile phase: A and B: $50 \% \mathrm{H}_{2} \mathrm{O}, 50 \% \mathrm{CH}_{3} \mathrm{OH}$. C: $60 \% \mathrm{H}_{2} \mathrm{O}, 30 \% \mathrm{CH}_{3} \mathrm{OH}, 10 \%$ $\mathrm{CH}_{3} \mathrm{CN}$. Detection: UV $(i=270 \mathrm{~nm})$. Peaks: A: 1,2 phenol +2 -chlorophenol; 3, 2,4-dichlorophenol; 4, 2-nitrophenol; 5, 4-nitrophenol; $\mathbf{B}$ and C: 1, phenol; 2, 2-chlorophenol; 3, 2,4-dichlorophenol; 4, 2-nitrophenol; 5, 4-nitrophenol

Table 3. Summary of results for the determination of substituted phenols

\begin{tabular}{ll}
\hline Sample & Linear equation $^{\mathrm{a}}$ \\
\hline Phenol & $\mathrm{y}=0.60 \mathrm{X}+1.22 \times 10^{3}(\mathrm{r}=0.9954)$ \\
2-Chlorophenol & $\mathrm{y}=0.32 \mathrm{X}+1.98 \times 10^{2}(\mathrm{r}=0.9997)$ \\
2,4-Dichlorophenol & $\mathrm{y}=0.12 \mathrm{X}+1.08 \times 10^{2}(\mathrm{r}=0.9991)$ \\
2-Nitrophenol & $\mathrm{y}=0.50 \mathrm{X}+2.65 \times 10^{1}(\mathrm{r}=0.9980)$ \\
4-Nitrophenol & $\mathrm{y}=0.09 \mathrm{X}-6.60 \times 10^{1}(\mathrm{r}=0.9978)$ \\
\hline
\end{tabular}

${ }^{a}$ Dynamic range: $0-2.4 \times 10^{-4} \mathrm{~mol} / \mathrm{L}$

copper and zinc resin complexes are 8.58 and 7.00 , respectively, which are somewhat smaller than those of the monomeric copper- or zinc-glycine complexes [8]. This phenomenon might possibly be due to a steric hindrance in the resin matrix.

Analytical application. The metal (copper or zinc)-resin complexes prepared as described in the previous paper [9] were used as stationary phases for the separation of phenolic compounds. Preliminary tests revealed that the five substituted phenols examined were not separated and coeluted from the underivatized S-CD column with mobile phases of $\mathrm{CH}_{3} \mathrm{CN} / \mathrm{H}_{2} \mathrm{O}(30 / 70), \mathrm{CH}_{3} \mathrm{OH} / \mathrm{H}_{2} \mathrm{O}$ $(50 / 50)$ or $\mathrm{CH}_{3} \mathrm{OH} / \mathrm{H}_{2} \mathrm{O}(35 / 65)$. However these compounds apparently yield a better resolution on a S-CDG-metal complex column. Methanol and acetonitrile were used as organic modifiers in the mobile phases. The elution order of the phenols on both S-CD-G-Cu and S$\mathrm{CD}-\mathrm{G}-\mathrm{Zn}$ columns with methanol-water is the same and the resolution was found to be better than with acetonitrile. An increased methanol content resulted in both a decreasing retention and separation efficiency (Tables 1 and 2). The combination of methanol with acetonitrile as 
a modifier brings about an increase of selectivity (Fig. 1). Since the separation mode was via ligand exchange, the stability constants of the metal complexes can be considered as a measure of how stable a solute with the central metal ion is. However, the elution order of the phenolic compounds is different from the predicted order. The exceptions were also examined by Petronio et al. in the separation of phenolic compounds with the Chelex100 iron complex as stationary phase [3]. According to Takayanagi's report, the stability of the inclusion complexes with $\beta-C D$ decreases in the following order: 4nitrophenol $\gg 4$-chlorophenol $\geq 2$-chlorophenol $\geq 2$-nitrophenol [10]. The result is consistent with the prediction. Carrying out the separation in this study was possible, despite the fact that the difference in the stability of the other three compounds with $\beta-C D$ is not so large $[10]$. As discussed above, the interaction of both ligand exchange and inclusion was assumed to improve the selectivity of the separation of phenolic compounds considerably and it is better than that of only the inclusion process or ligand exchange. The results also showed that a more efficient separation was achieved when the S-CD-G-Cu column was used instead of the S-CD-G-Zn column (Fig. 1).

Generally, methods for the determination of phenols in water are based on spectrophotometry [11]. However, this technique does not equally respond to all phenols, and the results for total phenols may be significantly erroneous. With the above LEC system, we were able to separate the phenols and reach detection limits of
$0.2 \mathrm{nmol}$ abs. per $20 \mu \mathrm{L}$ injection. The calibration graphs are summarized in Table 3.

Acknowledgement. We would like to thank the National Science Council of the Republic of China for its financial support (Grant No. NSC 81-0208-M-002-59).

\section{References}

1. Davankov VA, Navratil JD, Walton HF (1988) Ligand exchange chromatography. CRC Press, Florida

2. Gil-Av E, Tishbee A, Hare PE (1980) J Am Chem Soc 102: 5115

3. Petronio BM, De Caris E, Iannuzzi L (1982) Talanta 29: 691

4. Nimura N, Toyama A, Kasahara Y, Kinoshita T (1982) J Chromatogr 239: 671

5. Iwakura Y, Uno K, Toda F, Onozuka S, Hattori K, Bender ML (1975) J Am Chem Soc 97: 4432

6. Liu CY, Chen MJ, Lee NM, Hwang HC, Jou ST, Hsu JC (1992) Polyhedron 11: 551

7. Skoog DA, West DM, Holler FJ (1992) Fundamentals of analytical chemistry. Saunders, New York

8. Martell AE, Smith RM (1974) Critical stability constants. Plenum Press, New York

9. Yeh CF, Chen WS, Chyueh SD, Fan JD, Liu CY (1993) J Chromatogr 630: 275

10. Fujimura $\mathrm{K}$, Ueda $\mathrm{T}$, Masashi $\mathrm{K}$, Takayanagi $\mathrm{H}$, Ando T (1986) Anal Chem 58: 2668

11. Horwitz W (ed.) (1980) Official methods of analysis of the association of official analytical chemists. Washington, DC, USA 